\title{
The effect of a high-MUFA, low-glycaemic index diet and a low-fat diet on appetite and glucose metabolism during a 6-month weight maintenance period
}

\author{
Birgitte Sloth $^{1 *}$, Anette Due ${ }^{1}$, Thomas M. Larsen ${ }^{1}$, Jens J. Holst ${ }^{2}$, Anders Heding ${ }^{3}$ and Arne Astrup ${ }^{1}$ \\ ${ }^{1}$ Department of Human Nutrition, Centre for Advanced Food Studies (LMC), Faculty of Life Sciences, University of Copenhagen, \\ Rolighedsvej 30, 1958 Frederiksberg, Denmark \\ ${ }^{2}$ Department of Biomedical Sciences, The Panum Institute, University of Copenhagen, Blegdamsvej 3, 2200 Copenhagen N, \\ Denmark \\ ${ }^{3} 7$ TM Pharma, Fremtidsvej 3, 2970 Hoersholm, Denmark
}

(Received 18 April 2008 - Revised 1 October 2008 - Accepted 2 October 2008 - First published online 16 December 2008)

We aimed to test the effects of three different weight maintenance diets on appetite, glucose and fat metabolism following an initial low-energy diet (LED) induced body weight loss. Following an 8-week LED and a 2-3-week refeeding period, 131 subjects were randomized to three diets for 6 months: MUFA, moderate-fat (35-45 energy percentage (E\%) fat), high in MUFA with low glycaemic index; LF, low fat (20-30 E\% fat) or CTR, control (35 E\% fat). A meal test study was performed in a subgroup, before and after the 6-month dietary intervention, with forty-two subjects completing both meal tests. No difference in body weight, energy intake or appetite ratings were observed between diets. Both the LF and MUFA diets compared to CTR diet reduced postprandial glycaemia and insulinaemia and lowered fasting insulin from month 0 to month 6 . Following the 8-week LED period lower levels of the appetite regulating peptides, pancreatic polypeptide, peptide YY, glucagon-like peptide1 and glucagon-like peptide-2, along with increased appetite scores were seen in comparison to measurements performed after the 6-month dietary intervention. In conclusion, the two competing diets, MUFA and LF, were equally good with respect to glucose metabolism, whereas the CTR diet resembling the typical Western diet, high in SFA, sugar and high glycaemic carbohydrates, indicated associations to lowering of insulin sensitivity. Lower levels of appetite regulatory peptides along with increased appetite scores following an 8-week LED and 2-3-week refeeding period, suggest that strategies for physiological appetite control following a LED period are needed, in order to prevent weight regain.

Glycaemic response: Low-energy diet: MUFA diet: Low-fat diet: Gut peptides

In the ongoing battle against obesity and related diseases such as type 2 diabetes and CHD there is general agreement that SFA in the diet should be decreased, whereas total amount of dietary fat is still a matter of debate ${ }^{(1,2)}$. A diet high in MUFA can improve cardiovascular risk factors but this may be at the expense of a positive energy balance and increased body weight ${ }^{(3)}$. There is good evidence from randomized controlled trials that lowering dietary energy contribution from fat results in body weight loss ${ }^{(4-7)}$, but some scientists argue that adaptation to low-fat diets as well as lack of long-term compliance with low-fat diets is not taken into account by the randomized controlled trials, because most of these are short-term studies $^{(2,8)}$. In addition to fat, both the type and amount of carbohydrates of the diet have been in focus in relation to prevention of diet-related diseases. Interventions lowering the glycaemic response to foods, either by lowering the glycaemic index (GI) or the glycaemic load, have demonstrated improvement in risk markers for both type 2 diabetes and $\mathrm{CHD}^{(9,10)}$, whereas effects on appetite and body weight are conflicting ${ }^{(1,12)}$. Supplement-based low-energy diets (LED) are effective tools for body weight loss and promising results have been demonstrated in regards to glycaemic control and blood lipid profiles with these diets ${ }^{(13,14)}$. However, the challenge of weight maintenance following a body weight loss is known to be great, probably due to compensatory changes in a number of appetite regulatory peptides. Appetite regulatory peptides such as glucagon-like peptide-1 (GLP-1), peptide YY (PYY) and pancreatic polypeptide (PP), originating from the intestine and pancreas, are known to be important satiety signals ${ }^{(15,16)}$. The incretin hormones glucose-dependent insulinotropic polypeptide (GIP) and GLP-1 are also known to enhance postprandial insulin secretion and thereby lower the glycaemic response to a meal $^{(17,18)}$. PYY, GLP-1 and GLP-2 are all secreted from the intestinal L-cells but PYY and GLP-1 are both degraded by dipeptidyl aminopeptidase IV $^{(19-21)}$. Because GLP-2 is not degraded by dipeptidyl aminopeptidase IV it is considered a good marker of intestinal L-cell secretion and moreover its

Abbreviations: CTR, control diet; E\%, energy percentage; GI, glycaemic index; GIP, glucose-dependent insulinotropic polypeptide; GLP-1, glucagon-like peptide-1; GLP-2, glucagon-like peptide-2; HbA1c, glycated Hb; iAUC, incremental area under the curve; LED, low-energy diet; LF, low-fat diet; PP, pancreatic polypeptide; PYY, peptide YY; VAS, visual analogue scales.

* Corresponding author: Birgitte Sloth, fax +45 35332483, email bsl@life.ku.dk 
been shown to be implication in central appetite regulation, although peripheral administration in man has shown no effects on satiety ${ }^{(22-25)}$. The secretion of the different appetite-regulating peptides is partly dependent on total energy intake and may be affected differently by different diet types ${ }^{(26-28)}$.

The 4-year controlled dietary intervention trial 'Mufobes' (Monounsaturated Fatty Acids in Obesity) is ongoing at the Department of Human Nutrition. The aim of the trial is to compare the long-term effects of three diets, either high in monounsaturated fat (MUFA diet), low in fat (LF diet) or similar to the average Danish diet (control (CTR) diet), on body weight, body composition and risk factors for development of diet-related diseases following an initial $8 \%$ body weight loss by a LED diet. The aim of the present paper is, within a subgroup of the main study, to evaluate the effects of these three diets on fasting and postprandial appetite ratings, glucose, TAG, insulin, glucagon, GLP-1, GLP-2, GIP, PP and PYY concentration in response to a meal test performed at baseline (after the initial $8 \%$ body weight loss) and after 6 months of dietary intervention with the three different diet types.

\section{Experimental methods}

\section{Subjects}

Essentially the study was conducted as described previously $^{(29)}$. Of 169 screened participants, 154 participants fulfilled the inclusion criteria and were enrolled in the initial 8-week LED part of the trial. At the end of the 8-week weight-loss period 131 subjects were randomized to the three different diets and of these fifty-six were assigned to participate in the meal test, the results of which are the subject of the present paper. Forty-two of the original fifty-six subgroup subjects completed the full 6-month dietary intervention, and forty-one of these completed both the month 0 and month 6 meal test.

The inclusion criteria were: age 18-35 years, BMI $28-36 \mathrm{~kg} / \mathrm{m}^{2}$, body weight fluctuations $\leq 3 \mathrm{~kg}$ over the previous 2 months, non-smoker, healthy, systolic blood pressure $<180 \mathrm{mmHg}$, diastolic blood pressure $<100 \mathrm{mmHg}$. All subjects signed a consent declaration after having received written and oral information about the study protocol. The study was approved by the Ethical Committee of the Municipalities of Copenhagen and Frederiksberg and was carried out in accordance with the Helsinki declaration. The study is registered at ClinicalTrials.gov (Identifier $=$ NCT00274729).

\section{Experimental design}

Following screening, participants completed an 8-week LED period with 3.4-4.2 kJ/d (Nutrillett, Dansk Droge, Ishøj, Denmark). Participants who lost at least $8 \%$ of their initial body weight were allocated to one of the three dietary interventions using a simple block randomization procedure in which gender and initial BMI (below or above $32 \mathrm{~kg} / \mathrm{m}^{2}$ ) were used as stratification criteria. To ensure weight stabilization following the initial LED period, as well as adaptation to the supermarket model, the subjects were instructed to follow the CTR diet (described later) for 2-3 weeks prior to the meal test at baseline (month 0 ). The meal test was repeated following 6-month dietary intervention with the supermarket model (Fig. 1).

\section{Experimental diets and supermarket model}

Essentially the study was conducted as described previously $^{(29)}$. In brief the three prescribed ad libitum diets were (1) MUFA, moderate-fat (35-45 energy percentage (E\%) fat), high in MUFA (>20 E\%); (2) LF, low fat (20-30 E\% fat); and (3) CTR, control (35 E\% fat) with $>15$ E\% SFA. Protein was similar in all diets. Actual achieved dietary intake in the three intervention groups is presented in Table 1. The MUFA diet included more whole-grain foods, nuts and legumes, and aimed to have a lower GI than the other diets.

A validated supermarket model was used ${ }^{(30)}$. Subjects collected all foods (i.e. $100 \%$ of their energy needs) free of charge during the 3-week standardization and the 6-month dietary intervention periods. Approximately 700 different food items were available in the supermarket, but alcohol and soft drinks were not included. An estimated loss/increase of weight from preparation/cooking was accounted for and any non-supermarket foods eaten were registered. During the shopping session the energy percentage of fat, carbohydrate, protein, and content of MUFA, PUFA, SFA, fibre and added

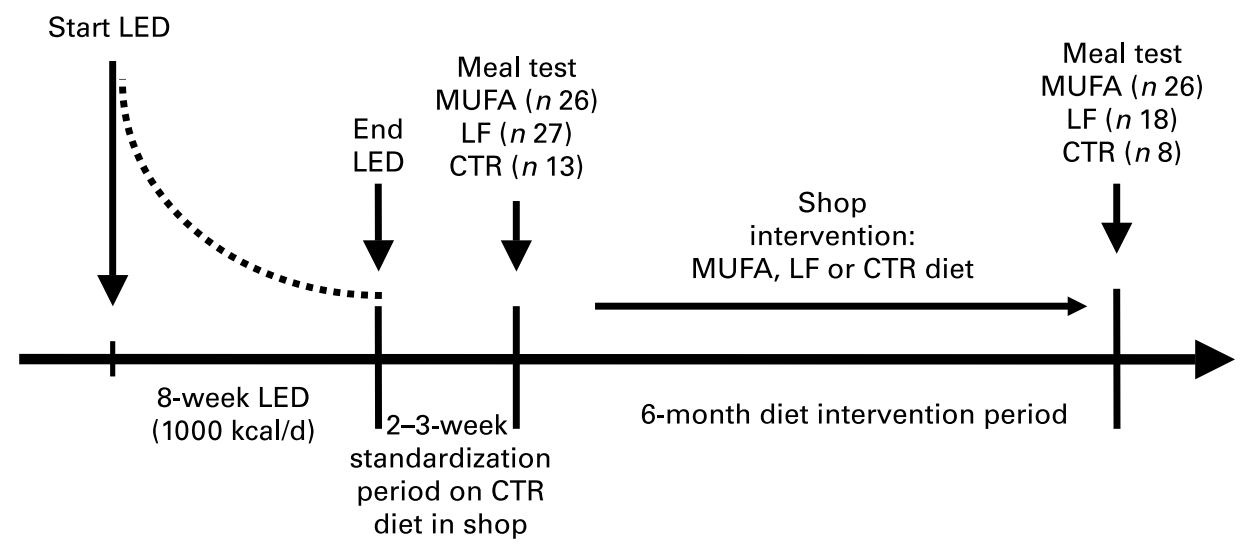

Fig. 1. Study design. CTR, control diet; LED, low-energy diet (3.4-4.2 kJ/d); LF, low-fat diet; ..., expected weight loss during the LED period of the study. 
Table 1. Energy intake, energy density and macronutrient composition of the three different diets during the 6-month supermarket intervention period*

(Mean values with their standard errors)

\begin{tabular}{|c|c|c|c|c|c|c|}
\hline & \multicolumn{2}{|c|}{ MUFA diet $(n 15)$} & \multicolumn{2}{|c|}{ LF diet $(n 18)$} & \multicolumn{2}{|c|}{ CTR diet ( $n 9)$} \\
\hline & Mean & SEM & Mean & SEM & Mean & SEM \\
\hline Energy intake (kJ/d) & 11799 & 1004 & 9625 & 626 & 10850 & 1066 \\
\hline Energy density $(\mathrm{kJ} / \mathrm{g}) \dagger$ & 4.9 & 0.2 & 3.6 & 0.1 & 4.5 & 0.3 \\
\hline Carbohydrate (E\%) & 43 & 1 & 57 & 0 & 50 & 1 \\
\hline Fat $(E \%)$ & 35 & 0 & 22 & 0 & 29 & 1 \\
\hline SFA (E\%) & 7 & 0 & 8 & 0 & 15 & 0 \\
\hline MUFA (E\%) & 20 & 0 & 8 & 0 & 10 & 0 \\
\hline PUFA (E\%) & 8 & 0 & 5 & 0 & 4 & 0 \\
\hline Protein (E\%) & 15 & 0 & 16 & 0 & 16 & 0 \\
\hline Fibre (g/10 MJ) & 39 & 1 & 36 & 2 & 28 & 2 \\
\hline Added sugar (E\%) & 5 & 0 & 8 & 0 & 10 & 1 \\
\hline
\end{tabular}

MUFA diet, moderate-fat high in MUFA diet; LF diet, low-fat diet; CTR diet, control diet; E\%, energy percentage. ${ }^{*}$ Calculations are based on the food tables from The National Food Agency of Denmark using Dankost 3000 software.

† Including water/drinks.

sugar were visible to both the study participant and the investigator, allowing adjustment of the purchase by adding and/or subtracting food items to achieve the correct dietary composition according to diet group. The total energy content of the foods was visible only to the investigator to assure that the shopping was ad libitum, though still allowing the investigator to estimate if the total amount of energy provided was within reasonable limits, based on number of days that the shopping session should cover, and on the age and body weight of the participant, and the participant's self-reported physical activity level ${ }^{(31)}$, with a maximum level set at $2 \cdot 0$.

All subjects received dietary counselling during shopping and had a minimum of two private counselling sessions with a dietitian during the 6 months.

\section{Anthropometric measurements}

Body weight was measured on an electronic scale (Lindell Tronic 8000; Samhall Lavi, Christianstad, Sweden) with subjects wearing only light clothing. Body composition was assessed by whole-body dual-energy X-ray absorptiometry scannings using a Lunar DPX-IQ (General Electrics, Madison, WI, USA) ${ }^{(32,33)}$. Height was measured to the nearest $0.5 \mathrm{~cm}$ using a wall-mounted stadiometer.

\section{Meal test}

On the test meal days subjects arrived at the Department at 07.30 hours having fasted from 20.00 hours. A venflon catheter was inserted in an antecubital vein. Following at least $10 \mathrm{~min}$ rest, two baseline blood samples were taken $5 \mathrm{~min}$ apart before the test meal was served at 08:00 hours $(t=0 \mathrm{~min})$. At 12.05 hours a second test meal was served and finally an ad libitum evening meal was served at 18:05 hours. Subjects had $10 \mathrm{~min}$ to consume the breakfast meal, $15 \mathrm{~min}$ for the lunch meal, whereas unlimited time was allowed for consumption of the ad libitum evening meal. The breakfast and lunch meal accounted for 20 and $33 \%$ of subject's daily energy requirements, which was calculated individually based on subjects $\mathrm{BMR}^{(34)}$ and a set physical activity level factor of 1.5 . The content of the breakfast and lunch meal is given in Table 2 and the macronutrient composition in Table 3. The ad libitum evening meal consisted of a homogenous pasta salad with $55 \mathrm{E} \%$ carbohydrate, $30 \mathrm{E} \%$ fat, $15 \mathrm{E} \%$ protein and $20 \mathrm{~g}$ fibre/10 MJ. During the entire test day blood samples were collected and $100 \mathrm{~mm}$ visual analogue scales (VAS) were used to measure hunger, satiety, prospective intake and fullness ${ }^{(35)}$. Before each blood sample subjects were instructed to assume a supine position for at least $10 \mathrm{~min}$.

\section{Laboratory analyses}

Venous blood was drawn without stasis through an indwelling antecubital cannula into iced syringes (except for glucose syringes, which were kept at room temperature). Syringes for glycated $\mathrm{Hb}$ (HbA1c), glucagon, GLP-1, GLP-2, GIP, PYY and PP contained EDTA. All samples were centrifuged at $2800 \mathrm{~g}$ for $15 \mathrm{~min}$ at $4^{\circ} \mathrm{C}$, except for $\mathrm{HbA} 1 \mathrm{c}$ samples, which were analysed on whole blood. Blood samples for insulin analysis were kept at $-80^{\circ} \mathrm{C}$, glucose samples were analysed the same day and all other samples were kept at $-20^{\circ} \mathrm{C}$ until analysis. HbA1c were analysed on COBAS INTEGRA 400 (Roche Diagnostic Systems, Basel, Switzerland) according to the Roche method manual: Hemoglobin A1c 2005-01, V 4 DA. Serum glucose concentration was analysed by standard end-point methods using Vitros 950 (Johnson \& Johnson, Ortho-Clinical Diagnistics, Rochester, NY, USA) with intraassay $\mathrm{CV}$ of $1.1 \%$. Serum insulin concentrations were measured by ELISA ${ }^{(36)}$. GIP, glucagon, GLP-1 and GLP-2 concentrations in plasma were all measured after extraction of plasma with $70 \%$ ethanol (v/v, final concentration). For the GIP RIA ${ }^{(37)}$ we used the C-terminally directed antiserum R 65, which cross-reacts fully with human GIP but not with the so-called GIP 8000, whose chemical nature and relationship to GIP secretion is uncertain. The antiserum reacts equally with intact GIP and GIP3-42, the primary metabolite. Human GIP and ${ }^{125}$ I-human GIP $(70 \mathrm{MBq} / \mathrm{nmol})$ were used for standards and tracer. The glucagon RIA was directed against the C-terminus of the glucagon molecule (antibody 
Table 2. The dietary composition of breakfast and lunch served during the test meal days in the moderate-fat high in MUFA (MUFA), low-fat (LF) and control (CTR) diets*

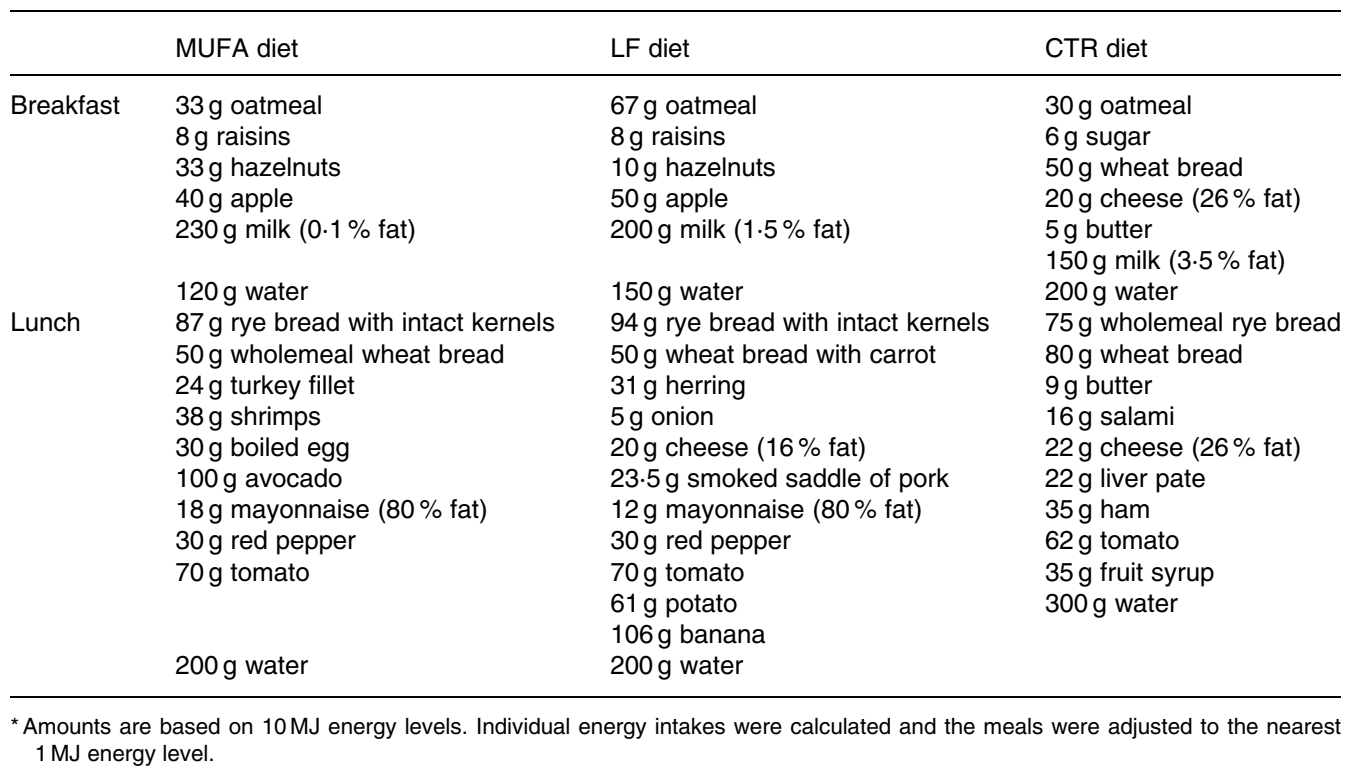

code no. 4305) and therefore mainly measures glucagon of

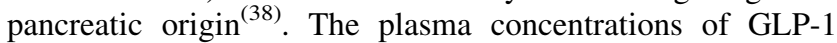
were measured $^{(39)}$ against standards of synthetic GLP-1 736 amide using antiserum code no. 89390, which is specific for the amidated C-terminus of GLP-1 and therefore mainly reacts with GLP-1 of intestinal origin. The assay reacts equally with intact GLP-1 and with GLP-1 3-36amide, the primary metabolite. Because of the rapid and intravascular conversion of both GIP and GLP-1 to their primary metabolites, it is essential to determine both the intact hormone and the metabolite for estimation of the rate of secretion of these hormones. GLP-2 was measured by RIA employing antiserum code no. 92160 and standards of human GLP-2 (proglucagon 126-158, a gift from Novo Nordisk A/S, Bagsværd, Denmark) and monoiodinated Tyr-12 GLP-1, specific activity $>70 \mathrm{MBq} / \mathrm{nmol}^{(40)}$. The antiserum is directed aganist the N-terminus of GLP-2 and therefore measures only fully processed active GLP-2 of intestinal origin. For all four assays sensitivity was $<2 \mathrm{pmol} / \mathrm{l}$, intra-assay $\mathrm{CV}<6 \%$ at $20 \mathrm{pmol} / \mathrm{l}$, and recovery of standard, added to plasma before extraction, about $100 \%$ when corrected for losses inherent in the plasma extraction procedure.

Plasma PYY was measured using the Linco PYY (total) RIA kit no. PYYT-66HK according to the manufacturer's protocol (Millipore, CHEMICON/Upstate/Linco, Billerica, MA, USA). Plasma PP was measured using a RIA established by 7TM Pharma (Hørsholm, Denmark). This RIA is based on a monoclonal antibody that primarily recognizes amino acids 20-23 of the PP molecule.

\section{Statistical analysis}

Results are reported as means and their standard errors. Results were considered significant when $P \leq 0 \cdot 05$. ANOVA was performed for BMI, body weight and fat mass with group, visit, and visit $\times$ group interactions tested. Differences between

Table 3. The macronutrient composition of breakfast and lunch served during the test meal days in the moderate-fat high in MUFA (MUFA), low-fat (LF) and control (CTR) diets*

\begin{tabular}{|c|c|c|c|c|c|c|}
\hline & \multicolumn{2}{|c|}{ MUFA diet } & \multicolumn{2}{|c|}{ LF diet } & \multicolumn{2}{|c|}{ CTR diet } \\
\hline & Breakfast & Lunch & Breakfast & Lunch & Breakfast & Lunch \\
\hline Energy density $(\mathrm{kJ} / \mathrm{g}) \dagger$ & 4 & 5 & 4 & 5 & 4 & 5 \\
\hline Carbohydrate (E\%) & 45 & 45 & 60 & 60 & 50 & 50 \\
\hline Fat (E\%) & 40 & 40 & 25 & 25 & 35 & 35 \\
\hline SFA (E\%) & 4 & 5 & 6 & 6 & 19 & 16 \\
\hline MUFA (E\%) & 27 & 23 & 12 & 11 & 10 & 12 \\
\hline PUFA (E\%) & 6 & 9 & 5 & 6 & 3 & 4 \\
\hline Protein (E\%) & 15 & 15 & 16 & 15 & 17 & 15 \\
\hline Fibre (g/10 MJ) & 7 & 17 & 9 & 15 & 5 & 11 \\
\hline Added sugar (E\%) & 0 & 0 & 0 & 3 & 5 & 7 \\
\hline
\end{tabular}

$\mathrm{E} \%$, energy percentage.

*Energy intake at the meals was adjusted to the nearest $1 \mathrm{MJ}$ level. Calculations are based on the food tables from The National Food Agency of Denmark using Dankost 3000 software.

†Including water/drinks. 
groups in height, age and fasting month 0 values were tested with one-way ANOVA. For the VAS ratings of appetite a mean appetite score was calculated individually by the formula:

Appetite score $=($ Satiety + Fullness $+(100$

$$
- \text { Prospective intake })+(100-\text { Hunger })) / 4 \text {. }
$$

All blood parameters and VAS measurements were tested with repeated measurement analysis of covariance with group, visit, time and interactions of these tested as main factors and with baseline values as covariates. When factors were non-significant the model was reduced successively. Differences between groups in all summary measures were analysed using ANOVA with group, visit and visit $\times$ group interactions tested. The summary measures were the incremental area under the curve (iAUC) or for the VAS parameters hunger and prospective intake the area over the curve but below baseline. These summary measures were calculated from baseline until $600 \mathrm{~min}\left(\mathrm{iAUC}_{\text {total }}\right.$ ), from baseline to $240 \mathrm{~min}$

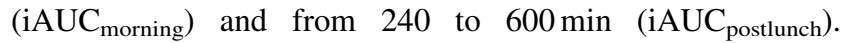
Calculations were made using the trapezoid rule leaving out the negative values. Differences in month 6 fasting values were tested with ANCOVA with group as main factor and month 0 fasting value as covariate. Differences in month 0 fasting values were tested with one-way ANOVA. Residual plots of data were examined to evaluate homogeneity of variance and the Shapiro-Wilk test was performed to test for normal distribution of data, and logarithmic and square root transformation was used when required. All statistical analyses were performed using Statistical Analysis Systems package version 9.1 (SAS Institute, Cary, NC, USA).

\section{Results}

\section{Anthropometrics}

There was a significant decrease in body weight, BMI and fat mass during the 8-week LED period, and a significant increase during the following 6-month dietary intervention, but with no differences between the three diet groups (Table 4).

\section{Ad libitum energy intake and visual analogue scale ratings of appetite}

The ad libitum energy intake at the evening test meal was not significantly different either between diet groups $\left(P_{\text {group }}=0 \cdot 42\right.$, data not shown) or between the month 0 and month 6 visit $\left(P_{\text {visit }}=0 \cdot 47\right.$, data not shown $)$.

The repeated measurement analysis of the mean appetite score demonstrated a significant time $\times$ visit interaction, with month 6 scores generally being higher (indicating increased satiety, fullness and decreased hunger and prospective intake) in comparison to month 0 scores, but with no significant difference between diet groups (Fig. 2). The present finding was supported by $\mathrm{iAUC}_{\text {total }}$ and $\mathrm{iAUC}_{\text {morning }}$ whereas for iAUC $_{\text {postlunch }}$ the difference between month 0 and month 6 was not significant $(P=0 \cdot 11)$ (Fig. 2).

\section{$T A G$, glucose, insulin, glucagon and glycated $\mathrm{Hb}$}

There were no differences between groups in fasting TAG, glucose, insulin and glucagon concentrations at month 0 or in fasting TAG, glucose and glucagon concentrations at month 6 (Table 5). Fasting month 6 insulin concentrations were lower in both the LF and MUFA groups compared to the CTR group (borderline significant, $P=0 \cdot 05$ ) (Table 5).

Table 4. Characteristics of subjects in the moderate-fat high in MUFA (MUFA), low-fat (LF) and control (CTR) groups before and after the low-energy diet (LED) period (month 0) and after the 6-month dietary intervention*

(Mean values with their standard errors)

\begin{tabular}{|c|c|c|c|c|c|c|}
\hline & \multicolumn{2}{|c|}{ MUFA $(n 15)$} & \multicolumn{2}{|c|}{$\mathrm{LF}(n 18)$} & \multicolumn{2}{|c|}{ CTR $(n 9)$} \\
\hline & Mean & SEM & Mean & SEM & Mean & SEM \\
\hline Sex, male/female & \multicolumn{2}{|c|}{$7 / 8$} & \multicolumn{2}{|c|}{$8 / 10$} & \multicolumn{2}{|c|}{$5 / 4$} \\
\hline Age (years) & 30 & 1 & 28 & 1 & 27 & 2 \\
\hline Height (cm) & 176 & 3 & 176 & 2 & 175 & 3 \\
\hline \multicolumn{7}{|l|}{ Body weight (kg) } \\
\hline Before LED & $95 \cdot 7$ & $3 \cdot 6$ & $95 \cdot 8$ & 3.4 & $98 \cdot 3$ & $4 \cdot 0$ \\
\hline After LED, month 0 & $85 \cdot 7$ & $3 \cdot 3$ & $84 \cdot 8$ & $2 \cdot 8$ & $87 \cdot 6$ & $3 \cdot 5$ \\
\hline After diet intervention, month 6 & $89 \cdot 3$ & $3 \cdot 7$ & $87 \cdot 4$ & 2.9 & $91 \cdot 7$ & 4.4 \\
\hline \multicolumn{7}{|l|}{ BMI $\left(\mathrm{kg} / \mathrm{m}^{2}\right)$} \\
\hline Before LED & $30 \cdot 7$ & 0.6 & $30 \cdot 8$ & 0.6 & $32 \cdot 0$ & 0.9 \\
\hline After LED, month 0 & $27 \cdot 5$ & 0.6 & $27 \cdot 3$ & 0.5 & $28 \cdot 5$ & 0.7 \\
\hline After diet intervention, month 6 & $28 \cdot 6$ & 0.7 & $28 \cdot 1$ & 0.6 & $29 \cdot 8$ & 0.9 \\
\hline \multicolumn{7}{|l|}{ Fat mass $(\mathrm{kg}) \dagger$} \\
\hline Before LED & $34 \cdot 2$ & 1.9 & $35 \cdot 5$ & $2 \cdot 3$ & $37 \cdot 1$ & $2 \cdot 7$ \\
\hline After LED, month 0 & $24 \cdot 4$ & 1.9 & $25 \cdot 7$ & $2 \cdot 2$ & $27 \cdot 3$ & $2 \cdot 8$ \\
\hline After diet intervention, month 6 & 27.5 & $2 \cdot 2$ & $27 \cdot 4$ & $2 \cdot 2$ & $31 \cdot 7$ & $3 \cdot 3$ \\
\hline
\end{tabular}

* For details of subjects and procedures, see Experimental methods. Two-way ANOVA analysis was performed for BMI, body weight and fat mass with group, time, and time $\times$ group interactions tested. There were no significant interaction effects, and no differences between groups. For both body weights, BMI and fat mass there were significant changes from before the LED to after the LED period and also from before and after the 6-month diet intervention. No differences were found between groups for height and age (one-way ANOVA analysis).

†Assessed by dual-energy X-ray absorptiometry scanning. 
(A)

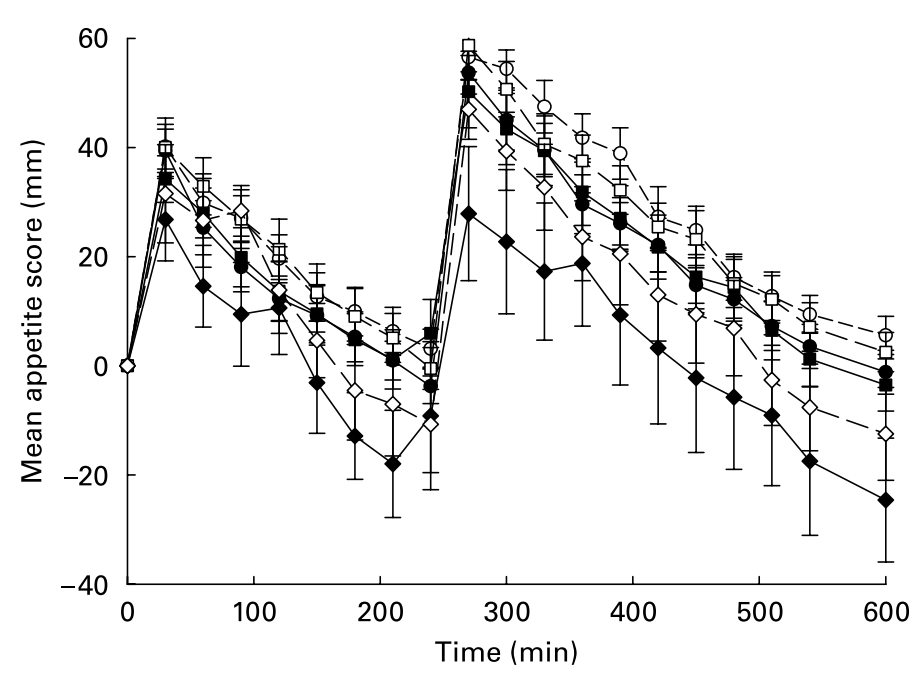

(B)

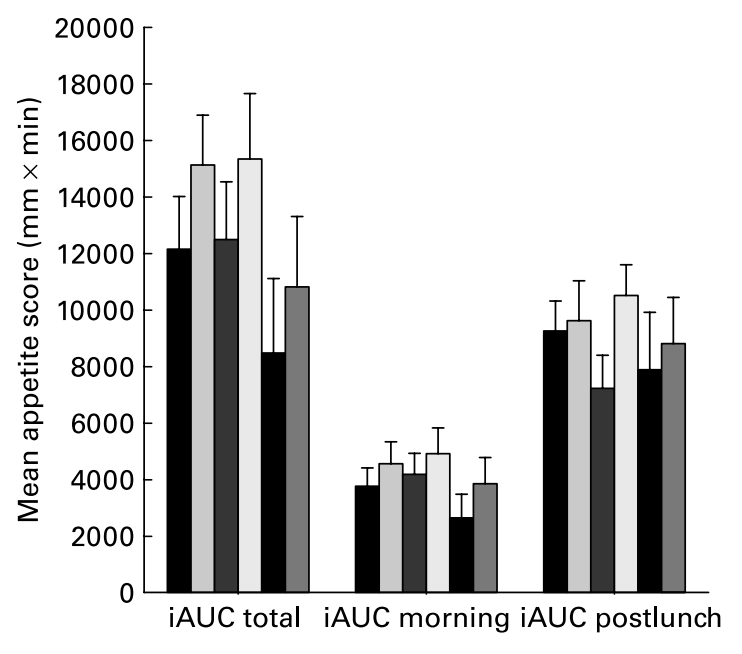

Fig. 2. (A), Changes from baseline in mean appetite score during meal test days before (month 0 visit) and after (month 6 visit) dietary intervention with MUFA diet ( $n$ 15; •, month 0 ; $\bigcirc$, month 6 ), low-fat diet (LF; $n$ 18; $\mathbf{\square}$, month 0 ; $\square$, month 6 ) and control diet (CTR; $n$; $\bullet$, month 0 ; $\diamond$, month 6$)$. Values are means with their standard errors depicted by vertical bars. Data were tested with repeated-measurement analysis of covariance, with diet group, visit and time as main factors and baseline value as cofactor: $P_{\text {visitxtime }}=0.04 ; P_{\text {group }}=0.7$. (B), Incremental areas under the curve (iAUC) for morning (time $0-240$ min), postlunch (time $240-$

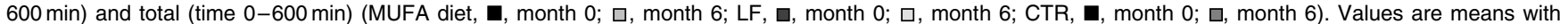
their standard errors depicted by vertical bars. Data were tested with two-way ANOVA, with diet group and visit as factors: morning, $P_{\text {visit }}=0.05$; lunch, NS; total, $P_{\text {visit }}=0.04$. Mean appetite score $=($ Satiety + Fullness $+(100-$ Prospective intake $)+(100-$ Hunger $)) / 4$.

HbA1c values were not different between groups at month 0 , but increased during the 6-month dietary intervention in the CTR group, and became significantly lower in both the LF and MUFA groups compared to the CTR group at month 6 $(P=0.03)$ (Table 5).

There was a significant group $\times$ time effect in the repeated measurement analysis of TAG $(P<0.0001$, data not shown), with the LF meals generally resulting in the lowest postprandial increases. Highest response following the breakfast test meal was in the CTR group and highest response following the lunch test meal was in the MUFA group, findings which were confirmed by the iAUC analysis.

There was a significant group $\times$ time effect in the repeatedmeasurement analysis of glucose $(P<0 \cdot 0001)$, with significantly lower glucose levels in the LF and MUFA groups compared to CTR group at time-points $30-60 \mathrm{~min}$ and $270-360 \mathrm{~min}$. Analysis of $\mathrm{iAUC}_{\text {postlunch }}$ confirmed the finding, with lower iAUC $_{\text {postlunch }}$ in both the LF and MUFA groups compared to the CTR group at month 6 . No significant differences were observed between groups or between visits for iAUC $\mathrm{ital}_{\text {tal }}$ $(P=0 \cdot 30)$ and iAUC $_{\text {morning }}(P=0 \cdot 55)$ (Fig. 3).

There was a significant group $\times$ time effect in the repeatedmeasurement analysis of insulin $\left(P_{\text {group } \times \text { time }}<0.0001\right)$, with highest postprandial responses both following breakfast and lunch for the CTR group, and the lowest responses in the MUFA group. The present finding was confirmed by the analysis of both $\mathrm{iAUC}_{\text {morning }}$ and $\mathrm{iAUC}_{\text {total }}$ revealing significant differences between groups with lowest values for the MUFA group and highest values for the CTR group. The only significant difference in $\mathrm{iAUC}_{\text {postlunch }}$ was a higher value for the CTR group at month 6 (Fig. 3).

A significant difference between groups in glucagon responses was observed $\left(P_{\text {group } \times \text { time }}=0.0002\right)$ with highest postlunch glucagon levels in the MUFA group and lowest postlunch levels in the CTR group. No significant differences were found in $\mathrm{iAUC}_{\text {morning }}\left(P_{\text {group }}=0.08\right)$ or $\mathrm{iAUC}_{\text {postlunch }}$ $\left(P_{\text {group }}=0 \cdot 23\right)$, but iAUC $_{\text {total }}$ was significantly higher in the MUFA group $\left(P_{\text {group }}=0 \cdot 02\right)$ (Fig. 3$)$.

Glucagon-like peptide-1, glucagon-like peptide-2 and glucosedependent insulinotropic polypeptide

There were no differences between groups in fasting GLP-1, GLP-2 or GIP either at month 0 or at month 6 (Table 5).

The repeated-measurement analysis of GLP-1 responses showed a significant visit effect with higher month 6 compared to month 0 values. A significant group $\times$ time interaction was also found with the post hoc analysis showing lower MUFA compared to CTR values at time $30 \mathrm{~min}$, lower LF compared to other groups at time $180 \mathrm{~min}$ and, finally, higher responses in the MUFA compared to the LF group from time-points $420-600 \mathrm{~min}$. The $\mathrm{iAUC}_{\text {morning }}$ was significantly higher at the month 6 compared to the month 0 meal test, but with no significant difference between diet

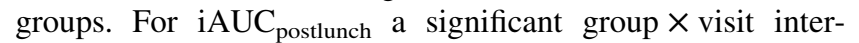
action was observed with significantly lower values for the CTR group at month 6 and LF at month 0 compared to the MUFA group at month 6 and LF at month 6 . No significant difference between groups or visit was found in $\mathrm{iAUC}_{\text {total }}$ (Fig. 4).

There was a significant group $\times$ time interaction in the repeated-measurement analysis of GLP-2, with the MUFA group generally having higher responses from min 306 to 600. Besides a significant higher month 6 compared to month 0 response was found. The $\mathrm{iAUC}_{\text {morning }}$ was significantly higher for the month 6 visit compared to the month 0 visit, whereas for the $\mathrm{iAUC}_{\text {postlunch }}$ a borderline significant group effect was found with highest response in the MUFA 
group compared to both LF and CTR groups. No difference between groups or visit was found in analysis of iAUC $\mathrm{Ctal}_{\text {tal }}$ (Fig. 4).

The repeated-measurement analysis showed a significantly lower GIP response following the breakfast test meal in the LF and MUFA groups compared to the CTR group $\left(P_{\text {group } \times \text { time }}=0 \cdot 0001\right)$. A significantly lower iAUC morning was observed in the MUFA group compared to the CTR group whereas no differences were seen in iAUC total or iAUC postlunch (Fig. 4).

\section{Pancreatic polypeptide and peptide $Y Y$}

There were no differences between groups in fasting PYY or PP either at month 0 or month 6 (Table 5). There was a significant group $\times$ time effect in the repeated-measurement analysis of PP $\left(P_{\text {group } x \text { time }}=0.002\right)$, with the LF group having higher concentrations compared to the MUFA group at the time-points 120 and $270 \mathrm{~min}$. Regarding the visit effect the PP responses were generally higher at month 6 compared to month $0 \quad\left(P_{\text {visit }}=0 \cdot 006\right)$. The analysis of iAUC $_{\text {morning }}$ showed no significant differences either between group or visit. Analysis of $\mathrm{iAUC}_{\text {postlunch }}$ showed a tendency to higher response at month 6 compared to the month 0 visit $\left(P_{\text {visit }}=0.07\right)$ and for iAUC total this difference was significant

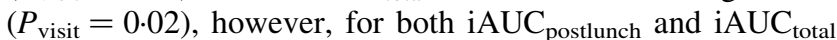
there were no differences between diet groups (Fig. 5).

There was a significant group $\times$ time effect in the repeatedmeasurement analysis of PYY $\left(P_{\text {timexgroup }}=0 \cdot 01\right)$, with the LF group having the highest postlunch concentrations and the CTR group the lowest. Analysing effects of visit, the PYY responses were generally higher at month 6 compared to month $0\left(P_{\text {visit }}=0.02\right)$. The analysis of iAUC showed a significantly higher $\mathrm{iAUC}_{\text {morning }}$ and $\mathrm{iAUC}_{\text {total }}$ at the month 6 visit compared to the month 0 visit but no significant differences between diet groups were found (Fig. 5).

\section{Discussion}

In the present study we found that the postprandial glycaemic response was significantly lowered by both the MUFA and the LF diets compared to the CTR diet, which suggests that the two competing diets are equally good alternatives to the habitual Western diet in terms of avoiding excessive postprandial glucose excursions. The clinical relevance of lowering the glycaemic response to meals has been a controversial matter, especially in regards to appetite regulation and body weight $^{(11,12)}$. The divergent results on the relation between GI, appetite and body weight might partly be due different study populations, since low glycaemic load diets have been demonstrated to have more pronounced effects in subjects with some degree of insulin resistance ${ }^{(41,42)}$. In the present population of overweight but otherwise healthy adults, there were no differences between the groups in body weight, BMI or fat mass changes although there was a numerically higher body weight and fat mass gain during the 6-month diet period in the MUFA compared to the LF group in this subgroup of the main study (Table 4). For anthropometric data on the full study group we refer to Due et al. ${ }^{(43)}$. However, results on glucose, insulin, glucagon and HbA1c following the 6-month weight maintenance period with a 

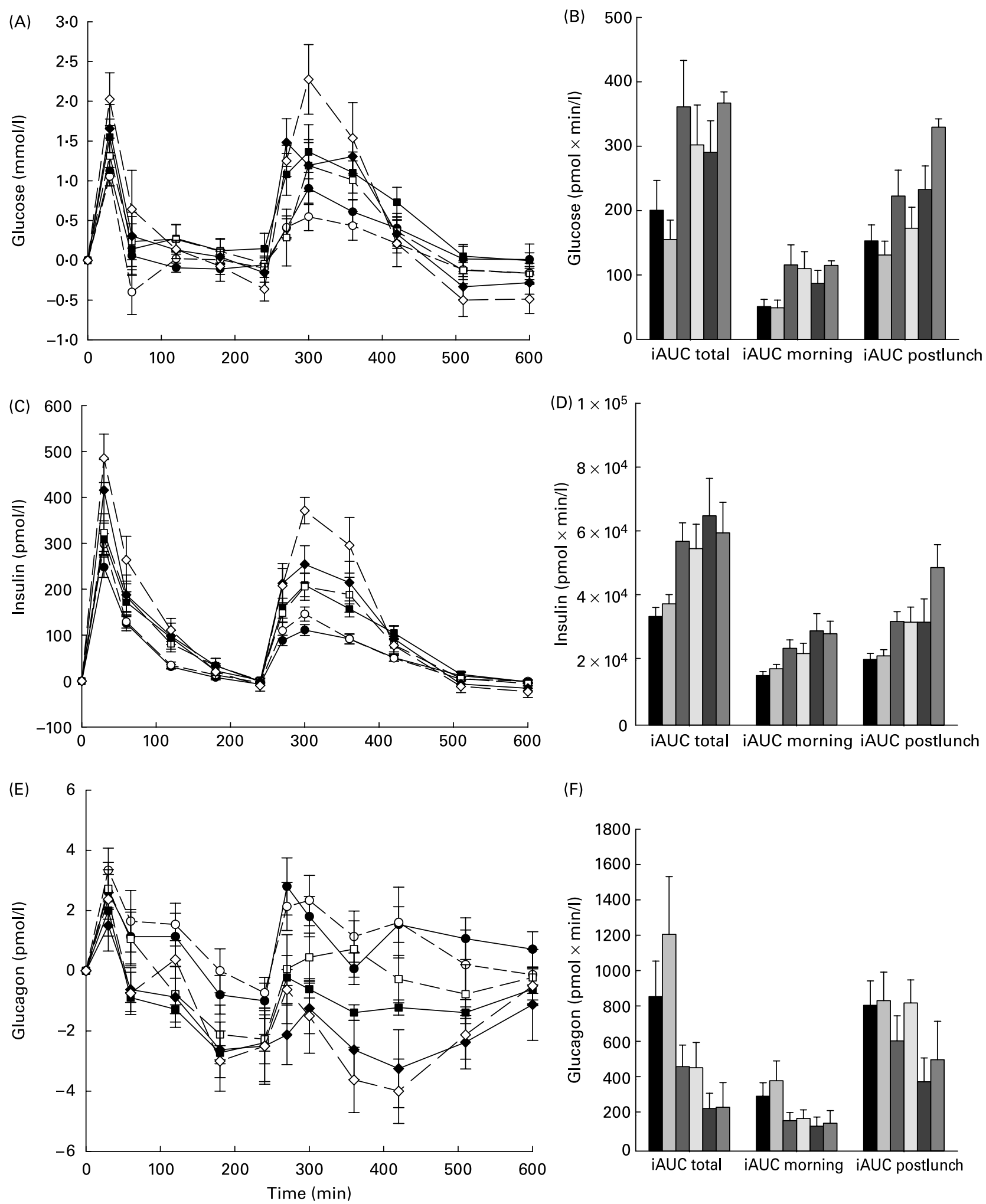

(F)

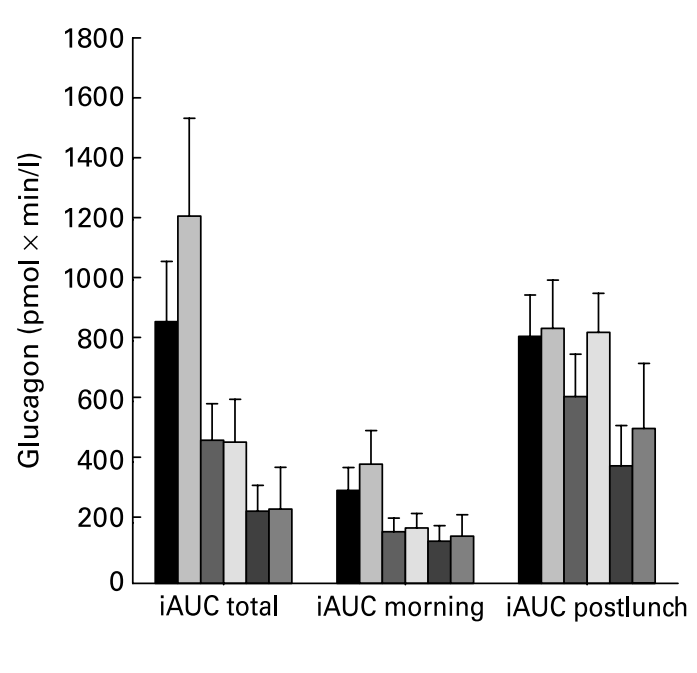

Fig. 3. Changes from baseline in glucose (A), insulin (C) and glucagon (E) during meal test days before (month 0 visit) and after (month 6 visit) dietary intervention with MUFA diet $(n 15 ; \bullet$, month $0 ; 0$, month 6$)$, low-fat diet (LF; $n 18 ; \mathbf{\square}$, month $0 ; \square$, month 6$)$ and control diet (CTR; $n 8 ; \bullet$, month $0 ; \diamond$, month 6$)$. Values are means with their standard errors depicted by vertical bars. Data were tested with repeated-measurement analysis of covariance, with diet group, visit and time as main factors and baseline value as cofactor: glucose, $P_{\text {group } x t i m e}=0.0001$; insulin, $P_{\text {group } x \text { time }}=0.0001$; glucagon, $P_{\text {group } x \text { time }}=0.0002$. (B, D, E), Incremental areas under the curve (iAUC) for morning (time 0-240 min), postlunch (time 240-600 min) and total (time 0-600 min) (MUFA diet, $\mathbf{\square}$, month 0; $\square$, month 6; LF, $\square$, month 0; $\square$, month 6; CTR, $\mathbf{m}$, month 0; $\square$, month 6). Values are means with their standard errors depicted by vertical bars. Data were tested with two-way ANOVA, with diet group and visit as factors: (B), morning, NS; postlunch, $P_{\text {group xvisit }}=0.03$; total, NS; (D), morning, $P_{\text {group }}=0.005$; postlunch, $P_{\text {group } x \text { visit }}=0.04$; total, $P_{\text {group }}=0.0004 ;$ (E), morning, NS; postlunch, NS; total, $P_{\text {group }}=0.02$. 

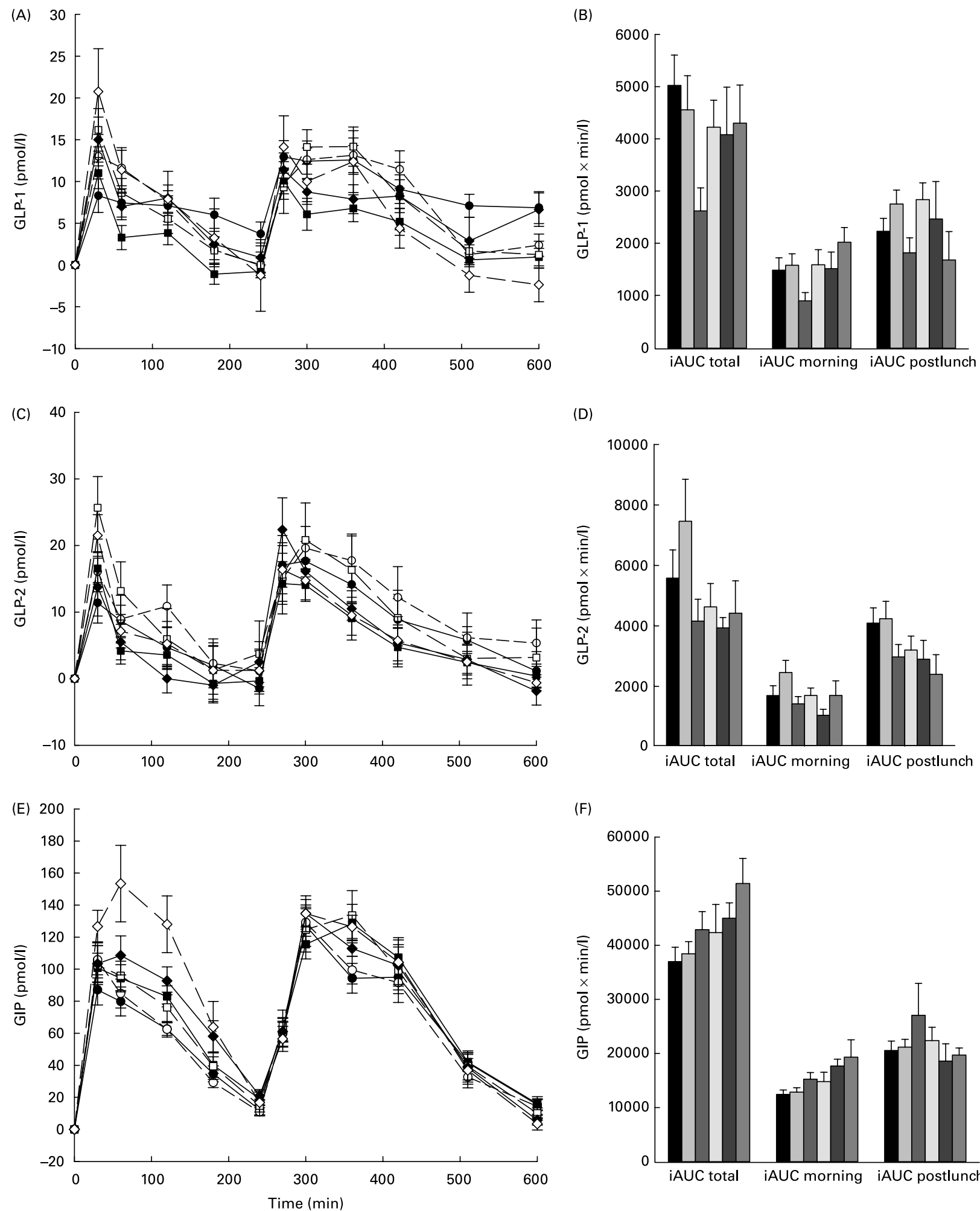

(F)

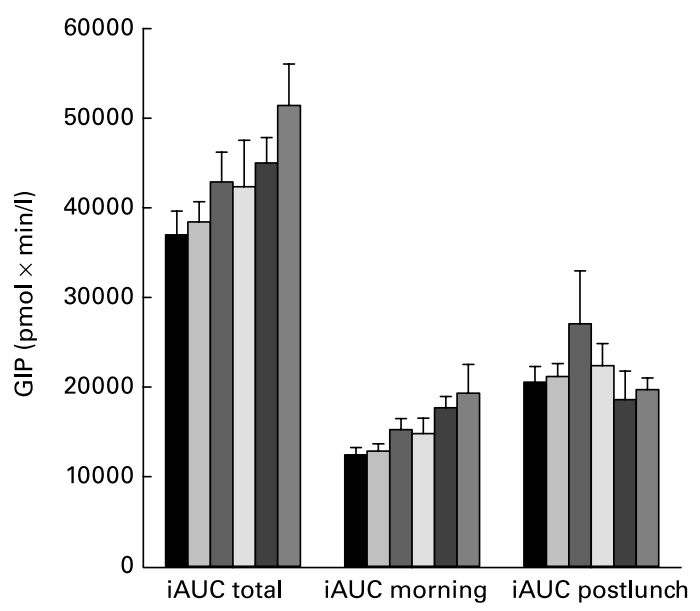

Fig. 4. Changes from baseline in glucagon-like peptide-1(GLP-1; A), glucagon-like peptide-2 (GLP-2; C) and glucose-dependent insulinotropic polypeptide (GIP; E) during meal test days before (month 0 visit) and after (month 6 visit) dietary intervention with MUFA diet $(n 15 ; \bullet$, month 0 ; O, month 6$)$, low-fat diet (LF; $n$ 18; $\mathbf{\square}$, month $0 ; \square$, month 6 ) and control diet (CTR; $n 8 ; \bullet$, month $0 ; \diamond$, month 6 ). Values are means with their standard errors depicted by vertical bars. Data were tested with repeated-measurement analysis of covariance, with diet group, visit and time as main factors and baseline value as cofactor: GLP-1, $P_{\text {groupxtime }}=0.03$, $P_{\text {visit }}<0.0001$; GLP-2, $P_{\text {groupxtime }}=0.008, P_{\text {visit }}<0.0001$; GIP, $P_{\text {group } x t i m e}=0.0001$. (B, D, E), Incremental areas under the curve (iAUC) for morning (time

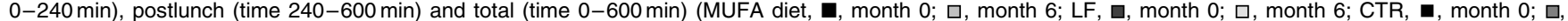
month 6). Values are means with their standard errors depicted by vertical bars. Data were tested with two-way ANOVA, with diet group and visit as factors: (B), morning, $P_{\text {visit }}=0.01$; postlunch, $P_{\text {groupxvisit }}=0.04$; total, NS; (D), morning, $P_{\text {visit }}=0.03$; postlunch, $P_{\text {group }}=0.05 ;$ total, NS; $(\mathrm{E})$, morning, $P_{\text {group }}=0.02$; postlunch, NS; total, NS. 
(A)

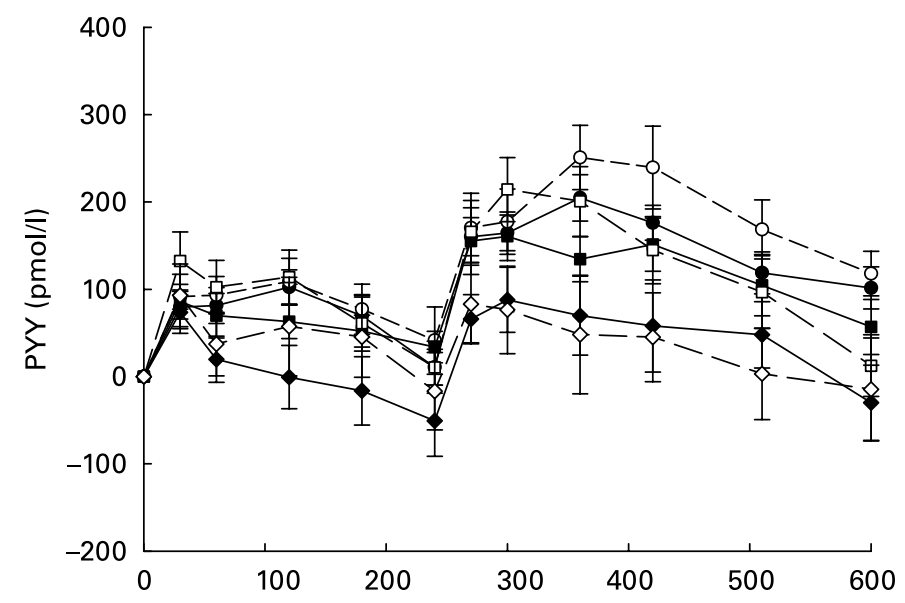

(B) $1.2 \times 10^{5}$

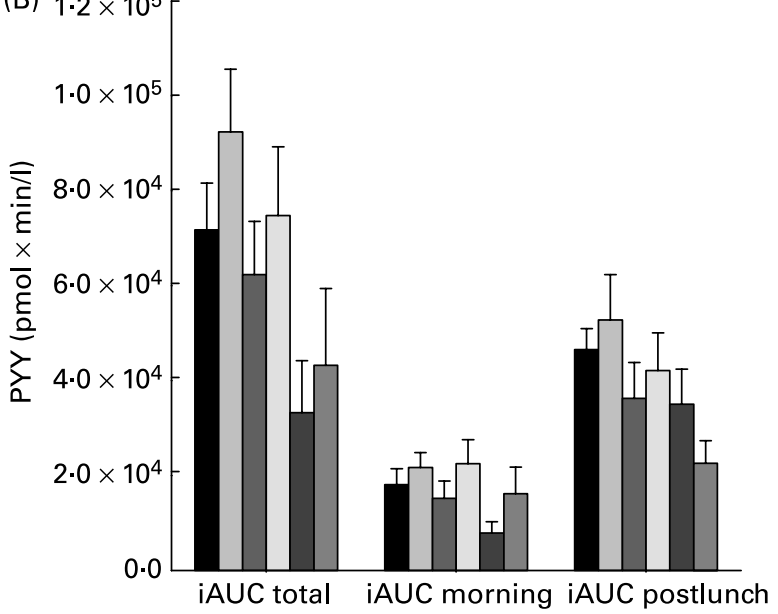

(C)

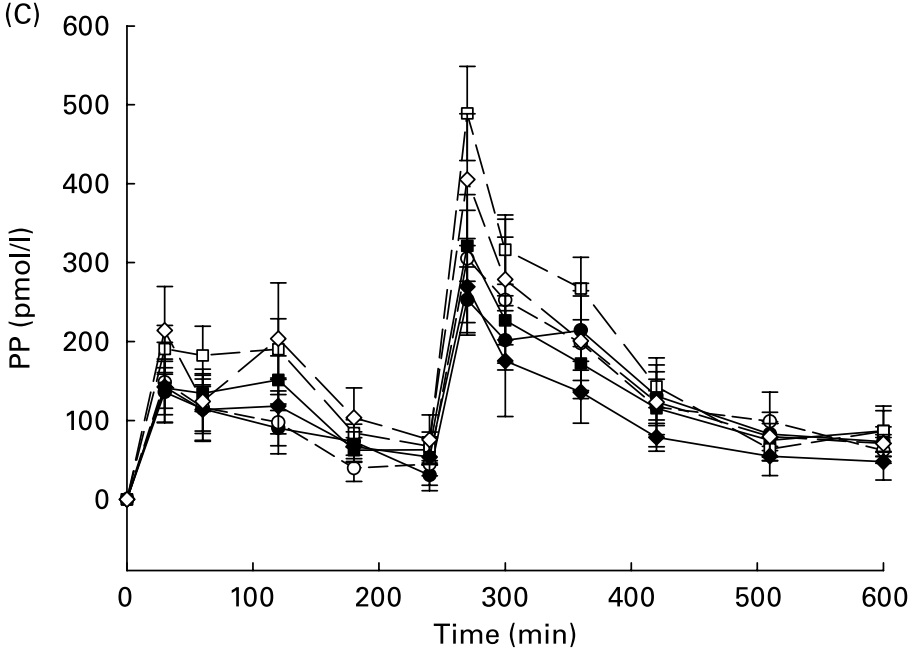

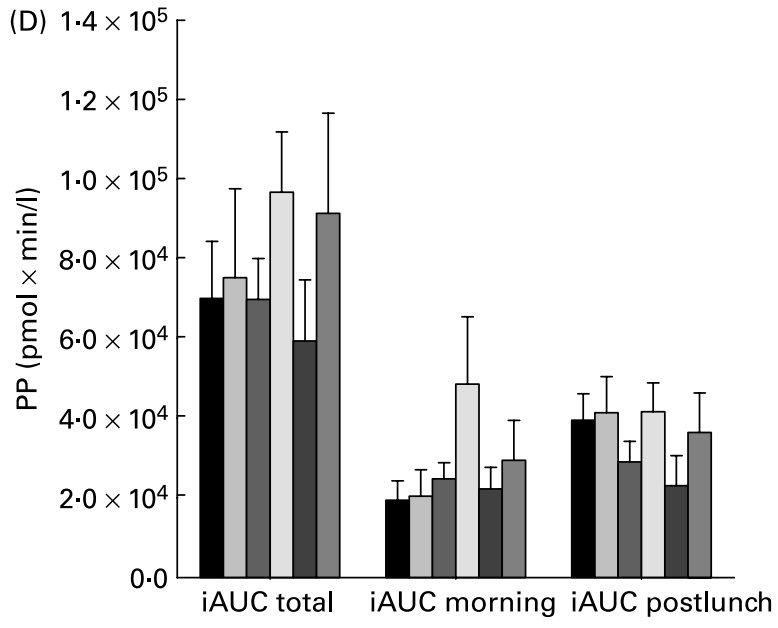

Fig. 5. Changes from baseline in peptide YY (PYY; A) and pancreatic polypeptide (PP; C) during meal test days before (month 0 visit) and after (month 6 visit) dietary intervention with MUFA diet $(n 15 ; \bullet$, month 0 ; $O$, month 6$)$, low-fat diet (LF; $n 18$; $\mathbf{\square}$, month 0 ; $\square$, month 6$)$ and control diet (CTR; $n$ 8; $\bullet$, month 0 ; $\diamond$, month 6). Values are means with their standard errors depicted by vertical bars. Data were tested with repeated-measurement analysis of covariance, with diet group, visit and time as main factors and baseline value as cofactor: PYY, $P_{\text {group } x \text { time }}=0.01, P_{\text {visit }}=0.02 ; \mathrm{PP}, P_{\text {groupxtime }}=0.002, P_{\text {visit }}<0.006$. (B, D), Incremental areas under the curve (iAUC) for morning (time 0-240 min), postlunch (time 240-600 min) and total (time 0-600 min) (MUFA diet, $\mathbf{\square}$, month 0; $\square$, month 6; LF, $\square$, month 0; $\square$, month 6; CTR, $\mathbf{a}$, month 0; $\square$, month 6). Values are means with their standard errors depicted by vertical bars. Data were tested with two-way ANOVA, with diet group and visit as factors: $(\mathrm{B})$, morning, $P_{\text {visit }}=0.02$; postlunch, Ns; total, $P_{\text {visit }}=0.03 ;(D)$, morning, NS; postlunch, NS; total, $P_{\text {visit }}=0.02$.

CTR diet revealed a pattern that could be suggestive of lowered insulin sensitivity, although it is important to state that glucose, insulin and $\mathrm{HbA1c}$ values were well within the normal range in all three diet groups.

The TAG responses were, as expected, lowest in the LF group, whereas differences between the two competing diets were less pronounced and varied during the test day. A higher postprandial glucose response was observed both after breakfast and lunch in the CTR group, indicating a higher glycaemic load of the CTR test meals compared to the other meals. The higher glycaemic response was accompanied by a larger insulin response, which is in accordance with theories on GI stating that calorie for calorie a highGI food will elicit a higher insulin response compared to a low-GI food ${ }^{(10)}$. The higher insulin response in the CTR group compared to other groups could be explained by the higher response of the incretin hormone GIP, observed following the CTR breakfast meal, but this difference was not apparent following the lunch meal. The higher insulin response following the lunch meal is therefore probably due, at least in part, to a second meal effect. The second meal effect describes the finding that a low-GI meal in comparison with a high-GI meal can improve glucose tolerance at a subsequent meal ${ }^{(44-46)}$. The likely mechanism behind this phenomenon relates to the late postprandial drop in glucose levels often seen with high-GI meals. This drop can trigger the counter-regulatory hormones (glucagon, epinephrine, corticol and growth hormone) in order to restore euglycaemia by increasing hepatic glucose output and lipolysis ${ }^{(10)}$. The resulting NEFA increase can then lead to increased insulin secretion during the second meal. In the long run this scenario might lead to decreased insulin sensitivity and type 2 
diabetes in genetically predisposed individuals ${ }^{(10,47)}$. Since the lunch meals in the present study were different according to diet group it is not possible to separate the effects of the second meal mechanism and the effect arising from differences in glycaemic load of the lunch meals, but it is interesting to note that the insulin levels both fasting and postprandial as well as the HbA1c values were significantly higher in the CTR group at month 6 . Thus, it could be speculated whether the CTR diet resembling the average Western diet in the longer run could decrease insulin sensitivity. The likely culprits of this diet compared to the LF and MUFA diet could be the higher intake of high-GI/low-fibre bread and cereals, as well as higher added sugar and SFA intake.

In regard to the present results relating to glucose metabolism it should be mentioned that results from a different subgroup of the Mufobes trial found that the MUFA diet lowered fasting glucose and insulin at month 6 compared to month 0 , whereas these values were elevated during the 6-month intervention period in both the CTR and LF groups ${ }^{(48)}$. In that subgroup an oral glucose tolerance test performed at months 0 and 6 revealed no differences between the three diet groups $^{(48)}$. Thus, there is a disagreement between the results from these two different subgroups of the Mufobes trial, in that the present study does not find differences between the two competing diets, MUFA and LF, on measurements related to glucose metabolism, whereas the results presented in Due et al. ${ }^{(48)}$ indicate that the MUFA diet could be superior to both the CTR and LF diets. This difference between results from the two subgroups of the Mufobes trial could be speculated to be due to both differences in the glucose tolerance between the two subgroups and/or the fact that the MUFA group presented in the present paper had a numerically higher mean energy intake during the 6-month intervention period and a higher body weight and fat mass regain compared to that of the CTR and LF groups.

To summarize the effects of the different diets on the appetite-regulating hormones: PP concentrations showed minor differences between groups with few time-points being higher in the LF group compared to the MUFA group. GLP1 , opposite to GIP, showed no clear pattern in its variations over time with the different diets. A higher GLP-2 level was seen in the MUFA group in the postlunch period and PYY postlunch values were highest in the MUFA compared to the CTR group. Although both GLP-2 and PYY were elevated in the postlunch period in the MUFA group compared to the other groups, no differences between diet groups in appetite ratings, ad libitum energy intake or body weight were seen in the present study.

In relation to effect of visit, GLP-1, GLP-2, PP and PYY all showed higher response at month 6 compared to month 0 . GLP-2 is a marker for general L-cell secretion, since its elimination is slow compared to that of at least GLP-1, which is rapidly cleaved by dipeptidyl aminopeptidase $\mathrm{IV}^{(21,49)}$. Therefore the finding of higher month 6 GLP-2 levels is in agreement with both the finding on PYY and GLP-1. Furthermore, GLP-2 is an important factor in the intestinal adaptation to food intake, both as a regulator of the epithelial cell mass and in regards to expression of intestinal transporters and transport proteins. The fact that GLP-2 concentrations were lower at the month 0 test meal compared to the month 6 test meal is thus probably a result of less L-cell and general epithelial cell activity following the LED period, and apparently the 2-3-week run-in period on CTR food was not long enough to restore normal intestinal function following the LED period. The lower level of the gut-derived satiety signals at month 0 compared to month 6 corresponded well with the lower mean appetite score in month 0 compared to month 6 , although no difference was seen in ad libitum energy intake. The lack of difference between diet groups in ad libitum energy intake could be due to both the timing of the meal $6 \mathrm{~h}$ after the lunch meal and the fact that subjects only had a total of $53 \%$ of their daily energy requirements served at breakfast and lunch, thus increasing the likelihood that the subjects were approaching a near-maximal hunger level, irrespective of their diet group. If the subjects had been served the ad libitum meal earlier (say 3-4h after lunch) or if more foods had been served during the day, differences might have been easier to detect. The lower levels of satiety hormones along with the increased hunger following the LED period (despite the 2-3-week re-feeding/stabilization period), could well explain why weight regain often follows LED periods and incorporation of a period with appetite-suppressive drug therapy should be considered as a possible strategy for weight maintenance following LED in the future.

To conclude, no differences in appetite, energy intake or body weight were seen between a LF, MUFA or CTR diet after a 6-month weight maintenance period in obese but otherwise healthy individuals. However, 6 months on the CTR diet resulted in significantly different glucose, insulin, glucagon and HbA1c values compared to both the MUFA and LF groups, indicating that a typical Western diet, high in SFA, sugar and high-glycaemic carbohydrates, could lead to decreased insulin sensitivity in genetically susceptible subjects in the long run. Finally, the present results demonstrated decreased levels of gut-derived satiety signals along with decreased ratings of satiety following an 8-week LED and 2-3-week refeeding period, suggesting that strategies for appetite control following a LED period are needed, in order to prevent weight regain.

\section{Acknowledgements}

The Mufobes study is sponsored by The H. A. Foundation, the Danish Heart Association, the Danish Diabetes Association, Centre for Advanced Food Research, the State Research Councils, LMC and the Danish Pork Council. Low-energy diets (formula) were sponsored by Nutrillett and foods were sponsored by The Danish Pork Council, Danisco, FDB, Arla Foods, 3-stjernet, Aarhus United, Allara, Ardo/Frigodan, Beauvais, Bæchs Conditori, Bähncke, Cadiso, Cerealia, Daloon, Danisco, FDB, Flensted, Frisko, G-kartofler, Gamba Food, Jan Import, Kellogg's, Kims, Kraft Foods, Kryta, Københavns Engros Grønttorv, Kødbranchens Fællesråd, LCH catering, Lykkeberg, Malaco Leaf, Nutana, Odense Marcipan, Polar Is, Puratos, Rose Poultry, Rynkeby, Saeby, Santa Maria, Schulstad, Svans $\varnothing$, Sønderjysk Kål, Tholstrup Cheese, Toms, Tulip, Unilever, Urtekram and Wasa. T. M. L. and A. A. were responsible for the first study protocol. A. D. and T. M. L. were responsible for conducting the trial and for data collection. J. J. H. was responsible for analysis of GLP-1, GLP-2, GIP and glucagon. A. H. was responsible for the analysis of PP and PYY. B. S. was responsible for data analysis and writing of the manuscript. A. A. was medical counsellor for the project. All authors contrib- 
uted to the interpretation of the results. None of the authors have any conflict of interest. The authors thank MSc Louise Jansen and technical staff at the Department of Human Nutrition for help with the execution of the clinical examinations, data collection and analysis and the subjects for their endurance throughout the study.

\section{References}

1. Astrup A (2002) Dietary fat is a major player in obesity - but not the only one. Obes Rev 3, 57-58.

2. Willett WC (2002) Dietary fat plays a major role in obesity: no. Obes Rev 3, 59-68.

3. Zock PL (2006) Do favourable effects of increasing unsaturated fat intake on cardiovascular disease risk outweigh the potential adverse effect on body weight? Int J Obes 30, S10-S15.

4. Astrup A, Grunwald GK, Melanson EL, et al. (2000) The role of low-fat diets in body weight control: a meta-analysis of ad libitum dietary intervention studies. Int J Obes Relat Metab Disord 24, 1545-1552.

5. Astrup A, Ryan L, Grunwald GK, et al. (2000) The role of dietary fat in body fatness: evidence from a preliminary meta-analysis of ad libitum low-fat dietary intervention studies. $\mathrm{Br}$ J Nutr 83, Suppl. 1, S25-S32.

6. Bray GA \& Popkin BM (1998) Dietary fat intake does affect obesity!. Am J Clin Nutr 68, 1157-1173.

7. Yu-Poth S, Zhao G, Etherton T, et al. (1999) Effects of the National Cholesterol Education Program's Step I and Step II dietary intervention programs on cardiovascular disease risk factors: a meta-analysis. Am J Clin Nutr 69, 632-646.

8. Willett WC (1998) Is dietary fat a major determinant of body fat? Am J Clin Nutr 67, S556-S562.

9. Kelly S, Frost G, Whittaker V, et al. (2004) Low glycaemic index diets for coronary heart disease. The Cochrane Database of Systematic Reviews 2004, issue 4, CD004467. http:// www.mrw.interscience.wiley.com/cochrane/clsysrev/articles/ CD004467/frame.html.

10. Ludwig DS (2002) The glycemic index: physiological mechanisms relating to obesity, diabetes, and cardiovascular disease. JAMA 287, 2414-2423.

11. Millan-Price J \& Brand-Miller J (2006) Low-glycaemic index diets and body weight regulation. Int $J$ Obes 30, S40-S46.

12. Sloth B \& Astrup A (2006) Low glycemic index diets and body weight. Int $J$ Obes 30, S47-S51.

13. Harder H, Dinesen B \& Astrup A (2004) The effect of a rapid weight loss on lipid profile and glycemic control in obese type 2 diabetic patients. Int J Obes Relat Metab Disord 28, 180-182.

14. Mustajoki P \& Pekkarinen T (2001) Very low energy diets in the treatment of obesity. Obes Rev 2, 61-72.

15. Wren AM \& Bloom SR (2007) Gut hormones and appetite control. Gastroenterology 132, 2116-2130.

16. Beglinger C \& Degen L (2006) Gastrointestinal satiety signals in humans - physiologic roles for GLP-1 and PYY? Physiol Behav 89, 460-464.

17. Dupre J, Ross SA, Watson D, et al. (1973) Stimulation of insulin secretion by gastric inhibitory polypeptide in man. $J$ Clin Endocrinol Metab 37, 826-828.

18. Kreymann B, Williams G, Ghatei MA, et al. (1987) Glucagonlike peptide-1 7-36: a physiological incretin in man. Lancet 2, $1300-1304$.

19. Grandt D, Dahms P, Schimiczek M, et al. (1993) Proteolytic processing by dipeptidyl aminopeptidase IV generates receptor selectivity for peptide YY (PYY). Med Klin (Munich) 88, 143-145.

20. Grandt D, Schimiczek M, Beglinger C, et al. (1994) Two molecular forms of peptide YY (PYY) are abundant in human blood: characterization of a radioimmunoassay recognizing PYY 1-36 and PYY 3-36. Regul Pept 51, 151-159.
21. Vilsboll T, Agerso H, Krarup T, et al. (2003) Similar elimination rates of glucagon-like peptide- 1 in obese type 2 diabetic patients and healthy subjects. J Clin Endocrinol Metab 88, 220-224.

22. Schmidt PT, Naslund E, Gryback P, et al. (2003) Peripheral administration of GLP-2 to humans has no effect on gastric emptying or satiety. Regul Pept 116, 21-25.

23. Sorensen LB, Flint A, Raben A, et al. (2003) No effect of physiological concentrations of glucagon-like peptide- 2 on appetite and energy intake in normal weight subjects. Int $J$ Obes Relat Metab Disord 27, 450-456.

24. Tang-Christensen M, Larsen PJ, Thulesen J, et al. (2000) The proglucagon-derived peptide, glucagon-like peptide- 2 , is a neurotransmitter involved in the regulation of food intake. Nat Med 6, $802-807$.

25. Jeppesen PB (2006) Glucagon-like peptide-2: update of the recent clinical trials. Gastroenterology 130, S127-S131.

26. Adrian TE, Ferri GL, Bacarese-Hamilton AJ, et al. (1985) Human distribution and release of a putative new gut hormone, peptide YY. Gastroenterology 89, 1070-1077.

27. Elliott RM, Morgan LM, Tredger JA, et al. (1993) Glucagonlike peptide-1 (7-36)amide and glucose-dependent insulinotropic polypeptide secretion in response to nutrient ingestion in man: acute post-prandial and 24-h secretion patterns. $J$ Endocrinol 138, 159-166.

28. Track NS, McLeod RS \& Mee AV (1980) Human pancreatic polypeptide: studies of fasting and postprandial plasma concentrations. Can J Physiol Pharmacol 58, 1484-1489.

29. Rasmussen LG, Larsen TM, Mortensen PK, et al. (2007) Effect on 24-h energy expenditure of a moderate-fat diet high in monounsaturated fatty acids compared with that of a low-fat, carbohydrate-rich diet: a 6-mo controlled dietary intervention trial. Am J Clin Nutr 85, 1014-1022.

30. Skov AR, Toubro S, Raben A, et al. (1997) A method to achieve control of dietary macronutrient composition in ad libitum diets consumed by free-living subjects. Eur J Clin Nutr 51, 667-672.

31. Bouchard C, Tremblay A, Leblanc C, et al. (1983) A method to assess energy expenditure in children and adults. Am J Clin Nutr 37, 461-467.

32. Haarbo J, Gotfredsen A, Hassager C, et al. (1991) Validation of body composition by dual energy X-ray absorptiometry (DEXA). Clin Physiol 11, 331-341.

33. Mazess RB, Barden HS, Bisek JP, et al. (1990) Dual-energy $\mathrm{X}$-ray absorptiometry for total-body and regional bone-mineral and soft-tissue composition. Am J Clin Nutr 51, 1106-1112.

34. World Health Organization (1985) Energy and Protein Requirements. Report of a Joint FAO/WHO/UNU Expert Consultation. WHO Technical Report Series no. 724. Geneva: WHO.

35. Flint A, Raben A, Blundell JE, et al. (2000) Reproducibility, power and validity of visual analogue scales in assessment of appetite sensations in single test meal studies. Int $J$ Obes Relat Metab Disord 24, 38-48.

36. Andersen L, Dinesen B, Jorgensen PN, et al. (1993) Enzyme immunoassay for intact human insulin in serum or plasma Clin Chem 39, 578-582.

37. Krarup T, Madsbad S, Moody AJ, et al. (1983) Diminished immunoreactive gastric inhibitory polypeptide response to a meal in newly diagnosed type I (insulin-dependent) diabetics. $J$ Clin Endocrinol Metab 56, 1306-1312.

38. Holst JJ (1982) Evidence that enteroglucagon (II) is identical with the C-terminal sequence (residues 33-69) of glicentin. Biochem J 207, 381-388.

39. Orskov C, Rabenhoj L, Wettergren A, et al. (1994) Tissue and plasma concentrations of amidated and glycine-extended glucagon-like peptide I in humans. Diabetes 43, 535-539.

40. Hartmann B, Johnsen AH, Orskov C, et al. (2000) Structure, measurement, and secretion of human glucagon-like peptide-2. Peptides 21, 73-80. 
41. Ebbeling CB, Leidig MM, Feldman HA, et al. (2007) Effects of a low-glycemic load vs low-fat diet in obese young adults: a randomized trial. JAMA 297, 2092-2102.

42. Pittas AG, Das SK, Hajduk CL, et al. (2005) A low-glycemic load diet facilitates greater weight loss in overweight adults with high insulin secretion but not in overweight adults with low insulin secretion in the CALERIE Trial. Diabetes Care 28, 2939-2941.

43. Due A, Larsen TM, Mu H, et al. (2008) Comparison of 3 ad libitum diets for weight-loss maintenance, risk of cardiovascular disease, and diabetes: a 6-mo randomized, controlled trial. Am $J$ Clin Nutr 88, 1232-1241.

44. Jenkins DJ, Wolever TM, Nineham R, et al. (1980) Improved glucose tolerance four hours after taking guar with glucose. Diabetologia 19, 21-24.
45. Jenkins DJ, Wolever TM, Taylor RH, et al. (1982) Slow release dietary carbohydrate improves second meal tolerance. Am J Clin Nutr 35, 1339-1346.

46. Wolever TM, Jenkins DJ, Ocana AM, et al. (1988) Second-meal effect: low-glycemic-index foods eaten at dinner improve subsequent breakfast glycemic response. Am J Clin Nutr 48, 1041-1047.

47. Boden $\mathrm{G}$ (2005) Free fatty acids and insulin secretion in humans. Curr Diab Rep 5, 167-170.

48. Due A, Larsen TM, Hermansen K, et al. (2008) Comparison of the effects on insulin resistance and glucose tolerance of 6-mo high-monounsaturated-fat, low-fat, and control diets. Am J Clin Nutr 87, 855-862.

49. Hartmann B, Harr MB, Jeppesen PB, et al. (2000) In vivo and in vitro degradation of glucagon-like peptide- 2 in humans. $J$ Clin Endocrinol Metab 85, 2884-2888. 